University of Nebraska - Lincoln DigitalCommons@University of Nebraska - Lincoln

Papers in Plant Pathology

Plant Pathology Department

2012

\title{
In Vitro Induction of Infection-Related Hyphal Structures in Plant Pathogenic Fungi
}

William R Rittenour

University of Nebraska-Lincoln

Steven D. Harris

University of Nebraska-Lincoln, Steven.Harris@umanitoba.ca

Follow this and additional works at: https://digitalcommons.unl.edu/plantpathpapers

Rittenour, William R and Harris, Steven D., "In Vitro Induction of Infection-Related Hyphal Structures in Plant Pathogenic Fungi" (2012). Papers in Plant Pathology. 274.

https://digitalcommons.unl.edu/plantpathpapers/274

This Article is brought to you for free and open access by the Plant Pathology Department at DigitalCommons@University of Nebraska - Lincoln. It has been accepted for inclusion in Papers in Plant Pathology by an authorized administrator of DigitalCommons@University of Nebraska - Lincoln. 


\title{
In Vitro Induction of Infection-Related Hyphal Structures in Plant Pathogenic Fungi
}

\author{
W. R. Rittenour and S. D. Harris \\ Department of Plant Pathology and Center for Plant Science Innovation, University of Nebraska, \\ Lincoln, NE, USA
}

Corresponding author - S. D. Harris, email sharris2@unl.edu

\begin{abstract}
In recent years, a voluminous amount of genomic data has been generated for several plant pathogenic fungi. Multiple studies have utilized these genomic data to advance our knowledge about the molecular mechanisms of plant pathogenesis. However, not all plant pathogenic fungi share the same infection strategies, and several genes have been identified that are crucial for plant pathogenesis in one fungus, but dispensable in others. In order for data on biological relevance to keep pace with accumulating genomic data, new biological assays need to be developed for several pathogenic fungi. Accordingly, we have developed an in vitro assay that allows us to monitor morphological changes in hyphal development as the head blight pathogen Fusarium graminearum infects wheat. Using previously frozen detached wheat glumes, we are able to monitor both subcuticular and intercellular hyphal development of $F$. graminearum. The method described takes only 3-5 days from inoculation to microscopic observation (depending on time point) and does not require any elaborate laboratory equipment or supplies. This method could be adapted for different necrotrophic or hemibiotrophic pathogens, on their host tissue types, in order to characterize their hyphal differentiation in vitro.
\end{abstract}

Keywords: Fusarium head blight, gibberella zeae, glume, infection hyphae, subcuticular hyphae

\section{Introduction}

Plant pathogenic fungi differentiate morphologically distinct hyphal structures at various times during infection. For example, the spores of the rice blast fungus, Magnaporthe oryzae, germinate and eventually differentiate a dome-shaped appressorium that mediates penetration of the rice leaf epidermis (1). The ability to induce M. oryzae appressoria in vitro has advanced the understanding of the physiological and genetic cues required for appressoria formation (2-4). A similar in vitro assay in other plant pathogenic fungi, coupled with the increase of readily available genomic data, will help elucidate the genetic requirements of infection-related development. 
Fusarium graminearum can cause a myriad of plant diseases, though it is most notorious for causing fusarium head blight of wheat and barley $(5,6)$. Many of the molecular requirements of pathogenicity and virulence have been elucidated over the past decade; however, a simple in vitro assay for pathogenic hyphal development was lacking. Unlike plant pathogenic fungi such as M. oryzae, F. graminearum does not differentiate an appressorium before invading plant tissue. However, it does differentiate coral-like subcuticular hyphae and wide dikaryotic hyphae upon wheat and barley invasion (7-9). We have used the following protocol to induce these infection-related structures in vitro and to demonstrate that the $\triangle g p m k 1 M A P K$ mutant is unable to induce wide bulbous infection hyphae (10).

\section{Materials}

\subsection{Inoculation Material}

1. Yeast Malt Extract Agar (YMA) plates: $4 \mathrm{~g}$ malt extract, $4 \mathrm{~g}$ sucrose, $4 \mathrm{~g}$ yeast extract, $15 \mathrm{~g}$ agar, to $1 \mathrm{~L}$ of deionized-distilled $\mathrm{H}_{2} \mathrm{O}\left(\mathrm{ddH}_{2} \mathrm{O}\right)$.

2. Carboxymethyl cellulose (CMC) liquid media: 15 g CMC (low viscosity, sodium salt), $1 \mathrm{~g}$ yeast extract, $1 \mathrm{~g} \mathrm{NH}_{4} \mathrm{NO}_{3}, 1 \mathrm{~g} \mathrm{KH}_{2} \mathrm{PO}_{4}, 0.25 \mathrm{~g} \mathrm{MgSO}_{4} \ldots 7 \mathrm{H}_{2} \mathrm{O}$.

3. Macroconidia of Fusarium graminearum: macroconidia can be generated in CMC media or on solid YMA plates (see Note 1).

4. $0.05 \%$ Tween 20 solution.

5. Frozen wheat heads: Collect wheat heads at anthesis from wheat variety "Norm." Store the wheat heads in a plastic bag at $-20^{\circ} \mathrm{C}$ (see Note 2 ).

6. Ultraviolet light for sanitizing wheat glumes.

7. $4 \%(\mathrm{w} / \mathrm{v})$ water agar.

\subsection{Components for Fixing Inoculated Glumes}

1. 24-well cell culture plate.

2. Clearing solution A: $75 \mathrm{~mL}$ ethanol, $25 \mathrm{~mL}$ glacial acetic acid.

3. Clearing solution B: $50 \mathrm{~mL}$ ethanol, $10 \mathrm{~mL}$ glacial acetic acid, $10 \mathrm{~mL}$ glycerol.

4. Lactophenol blue staining solution: $13.5 \mathrm{~mL}$ lactic acid, $13.5 \mathrm{~mL}$ phenol, $12 \mathrm{~mL} \mathrm{ddH_{2 }} \mathrm{O}_{\text {, }}$ $1 \mathrm{~mL} 0.4 \%$ trypan blue solution.

5. Destain solution: $60 \mathrm{~mL}$ glycerol, $40 \mathrm{~mL} \mathrm{ddH_{2 }} \mathrm{O}$. 


\subsection{Components for Dissecting/Mounting Fixed Glumes}

1. Dissecting microscope.

2. Surgical Scalpel.

3. Fine metal forceps.

4. Microscope slides and coverslips.

5. Bright-field compound microscope with camera (camera optional).

\section{Methods}

\subsection{Growth of F. graminearum on Solid YMA or Liquid CMC Media to Produce Macroconidia}

1. Inoculate YMA plates or $50 \mathrm{~mL}$ CMC media with $50 \mu \mathrm{L}$ of a $1 \times 10^{5}$ macroconidia suspension (see Note 1).

2. If using YMA plates to generate macroconidia, place the inoculated plates in an incubaotary shaker set ator set at $28^{\circ} \mathrm{C}$. Incubate for $4-5$ days.

3. If using liquid CMC cultures to generate macroconidia, place the $50 \mathrm{~mL}$ cultures in a rt $200 \mathrm{rpm}$ and $25^{\circ} \mathrm{C}$ for 5 days.

\subsection{Harvest the Macroconidia}

1. If using YMA, add $1.5 \mathrm{~mL}$ of $0.05 \%$ tween to the plate and release macroconidia with a sterile-glass rod. Collect macroconidia suspension and filter through miracloth (Calbiochem) to remove hyphal debris.

2. If using $\mathrm{CMC}$, filter the media/spore suspension through miracloth to remove hyphal debris.

3. Assess the macroconidia concentration with a hemacytometer and dilute to $1 \times 10^{6}$ in $0.05 \%$ tween.

\subsection{Prepare Wheat Glumes for Inoculation}

1. Remove wheat heads from $-20^{\circ} \mathrm{C}$. Carefully remove glumes from the florets and place on $4 \%$ water agar with the cavity (adaxial side) facing up (see Note 3; Figure 1).

2. Place water agar plates, without lids, under an ultraviolet light for 30-60 s to sanitize the glumes.

\subsection{Inoculate and Incubate Detached Wheat Glumes}

1. Collect $2000 \mathrm{~L}$ of macroconidia suspension (concentration between $10^{4}$ and $10^{6}$ macroconidia per $\mathrm{mL}$; see Note 4 ) in a P200 micropipettor.

2. Aliquot approximately 20-30 $\mathrm{LL}$ of the suspension onto the adaxial side of each glume (see Note 3; Figure 1).

3. Incubate the glumes at room temperature for $1 \mathrm{~min}$, and then remove the macroconidia suspension from the glumes.

4. Incubate the wheat glumes at room temperature for given time points (see Note 5). 

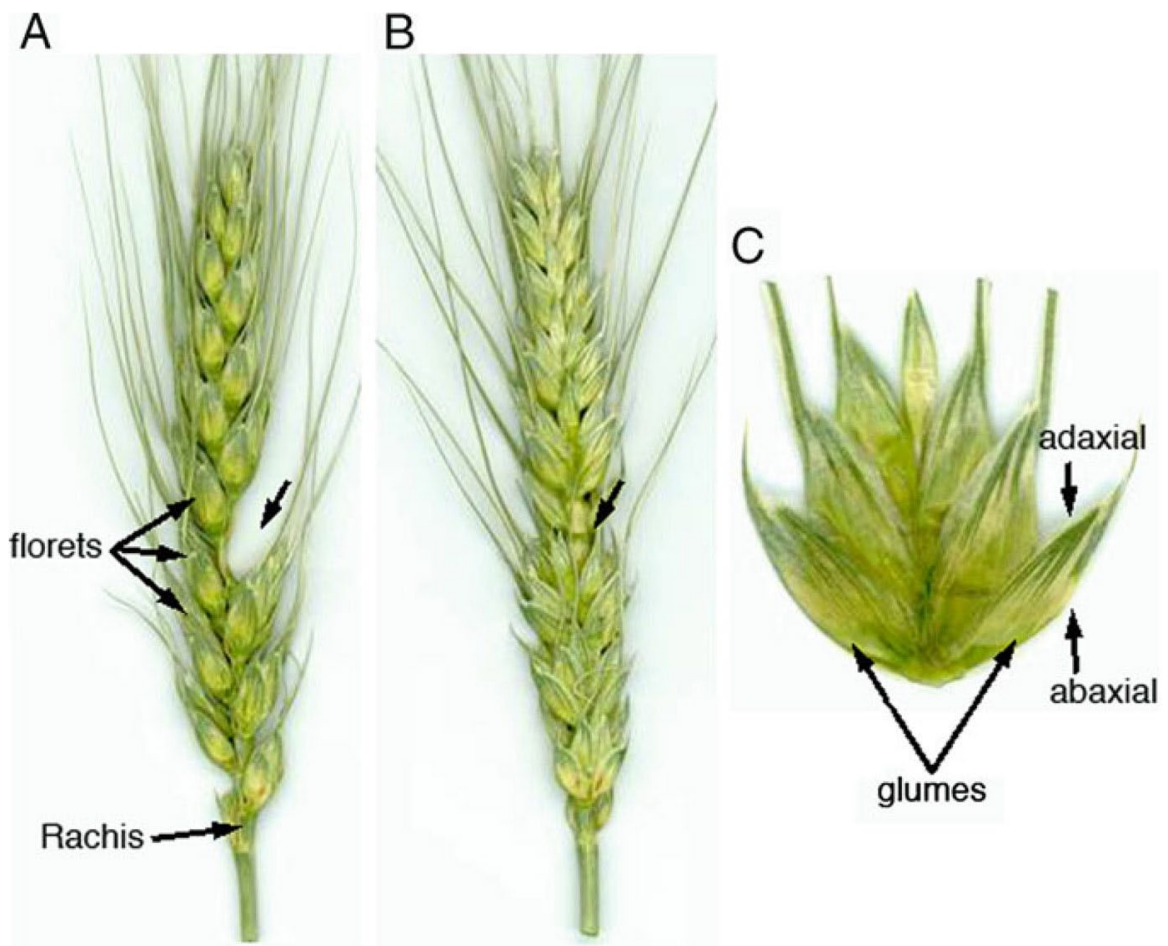

Figure 1. Wheat heads and florets. (a) Side view of wheat head showing rachis, florets, and area where a floret was detached (arrow). (b) Front view of a wheat head showing where floret was detached (arrow). (c) Detached floret showing the abaxial and adaxial side of wheat glumes.

\subsection{Fixing and Mounting Wheat Glumes for Microscopy}

1. After a given time point, remove glumes from water agar plate and place into well of 24-well cell culture plate containing $1 \mathrm{~mL}$ of clearing solution A (see Note 6). Incubate overnight $(\sim 16 \mathrm{~h})$ at $75 \mathrm{rpm}$ and room temperature.

2. Move the glumes to another well containing $1 \mathrm{~mL}$ clearing solution $\mathrm{B}$. Incubate for 4 $\mathrm{h}$ at $75 \mathrm{rpm}$ and room temperature.

3. Move the glumes to another well containing $1 \mathrm{~mL}$ of lactophenol blue staining solution (see Note 7$)$. Incubate overnight ( $16 \mathrm{~h})$ at $75 \mathrm{rpm}$ and room temperature.

4. Move glumes to another well containing $1 \mathrm{~mL}$ of $60 \%$ glycerol for $5 \mathrm{~min}$ to remove most of the residual lactophenol blue. After 5 min incubation, move to fresh $60 \%$ glycerol and incubate for at least $3 \mathrm{~h}$.

5. With the aid of a dissecting scope, use the forceps and surgical scalpel to cut washed glumes into $\sim 1 \mathrm{~mm}^{2}$ sections for oblique views or $0.25 \mathrm{~mm}$ thick strips for cross-section views (see Note 8).

6. Move the sections to a microscope slide containing $~ 50 \mu \mathrm{L} 60 \%$ glycerol. Overlay with coverslip and examine under microscope (see Figure 2 for some expected results). 

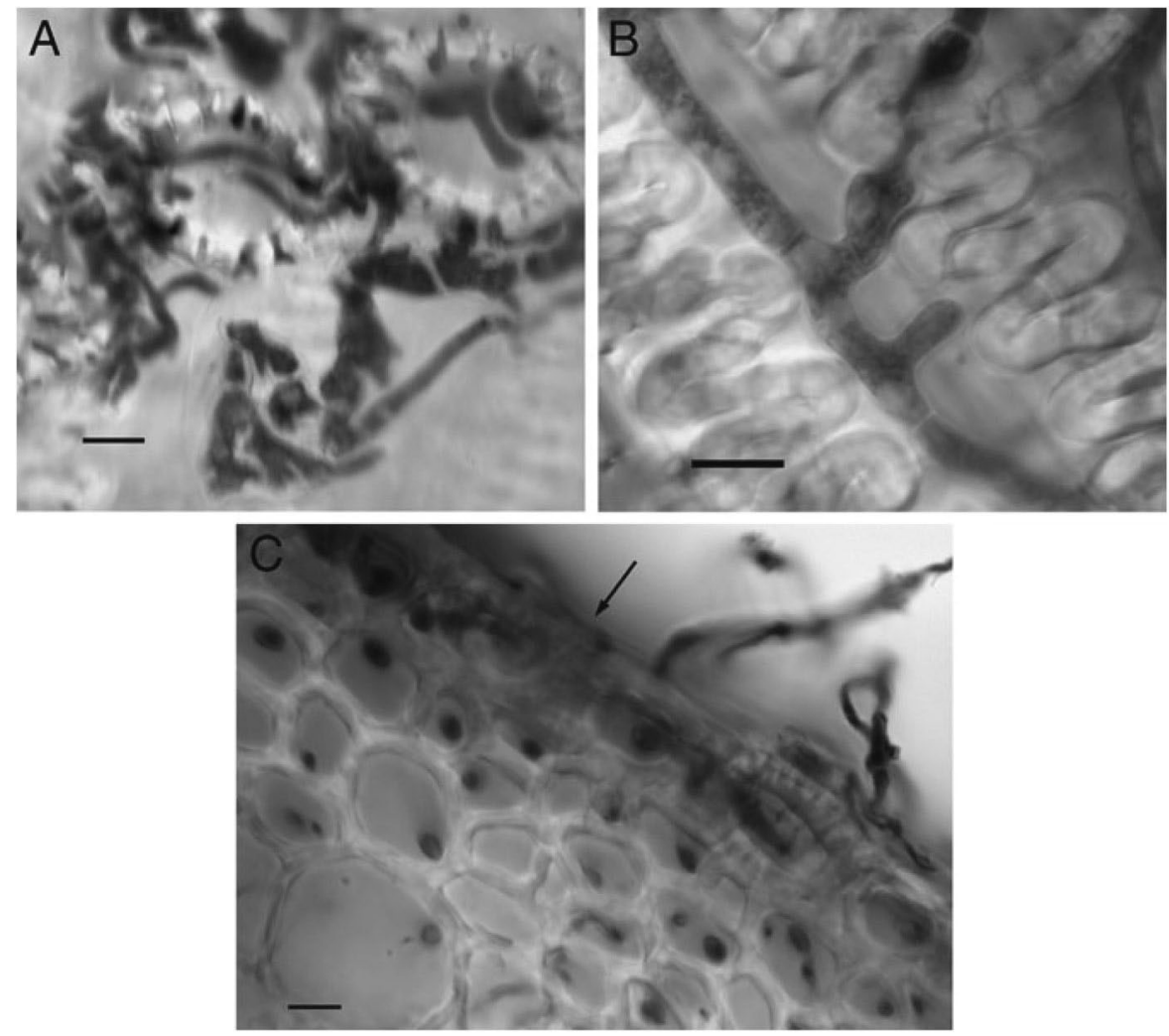

Figure 2. Some expected results. (a) Coral-like subcuticular hyphae after $24 \mathrm{~h}$. (b) Bulbous infection hyphae after 48 h. (c) Cross-section view of glume inoculated on adaxial side (arrow). Note the invasion of lower mesophyll cells by F. graminearum hyphae. Hyphae in all panels stained with lactophenol trypan blue. Scale bar $=10 \mu \mathrm{m}$ in all panels.

\section{Notes}

1. Many laboratories use CMC to generate F. graminearum macroconidia, and it has become an accepted standard for the generation of macroconidia; we have also had good results using this method. However, we obtain 10-100-fold more macroconidia when using YMA, and some of the mutants generated in our laboratory do not sporulate well in CMC. Users are encouraged to try both methods and see which works better for their given scenario.

2. Subcuticular and bulbous invasion hyphae are more readily formed on previously frozen glumes compared to freshly detached wheat glumes (unpublished data).

3. We have inoculated macroconidia and ascospores on both the abaxial and adaxial side of wheat glumes (10). On the abaxial side, the hyphae appear to readily penetrate stomata, but the development of morphologically distinct structures is not as common as when the spores are inoculated onto the adaxial side of the glume. 
4. When beginning our experiments, overinoculation often caused heavy invasion and staining that made distinguishing morphological structures difficult. We have since had success with macroconidia concentrations between $5 \times 10^{4} \mathrm{~mL}^{-1}$ and $1 \times 10^{6}$ $\mathrm{mL}^{-1}$. Before pursuing these experiments, we recommend users empirically test various macroconidia concentrations to see which yield suitable results.

5. Subcuticular hyphae and bulbous invasion hyphae are readily observed at the $24 \mathrm{~h}$ incubation time point when F. graminearum strain PH-1 and wheat variety "Norm" are used (Figure 2) (10). However, 48 and $72 \mathrm{~h}$ may be necessary for slower-growing mutants. Also, bulbous infection hyphae are often more prevalent after $48 \mathrm{~h}$, as they stain very lightly after only $24 \mathrm{~h}$.

6. In order to save supplies, we often include two glumes of the same treatment type per well when clearing/staining hyphae.

7. While we describe staining with lactophenol blue, we also have stained with calcofluor white and observed infection-related hyphae with fluorescent microscopy (10). Also, we have used a F. graminearum strain that constitutively expresses GFP (kindly provided by Dr. Jin-Rong $\mathrm{Xu}$, Purdue University) and electron microscopy to observe these hyphal structures (unpublished data; 10).

8. Certain sections of the wheat glume appear to be more conducive to microscopic observation. Some parts (especially near the base of the glume or near the midrib) are too thick for mounting on a slide and/or background stain heavily with lactophenol blue.

\section{References}

1. Howard RJ, Valent B (1996) Breaking and entering: host penetration by the fungal rice blast pathogen Magnaporthe grisea. Ann Rev Microbiol 50:491-512

2. Mitchell TK, Dean RA (1995) The cAMP-dependent protein kinase catalytic subunit is required for appressorium formation and pathogenesis by the rice blast pathogen Magnaporthe grisea. The Plant Cell 7:1869-1878

3. Xu J-R, Hamer JE (1996) MAP kinase and cAMP signaling regulate infection structure formation and pathogenic growth in the rice blast fungus Magnaporthe grisea. Genes \& Devel 10:2696-2706

4. Takano Y, Choi W, Mitchell TK, Okuno T, Dean RA (2003) Large scale parallel analysis of gene expression during infection-related morphogenesis of Magnaporthe grisea. Mol Plant Pathol 4:337-346

5. McMullen M, Jones R, and Gallenberg D (1997) Scab of Wheat and Barley: A re-emerging disease of devastating impact. Plant Dis 81:1340-1348

6. Goswami RS, Kistler HC (2004) Heading for disaster: Fusarium graminearum on cereal crops. Mol Plant Pathol 5:515-525

7. Pritsch C, Muehlbauer GJ, Bushnell WR, Somers DA, Vance CP (2000) Fungal development and 
induction of defense response genes during early infection of wheat spikes by Fusarium graminearum. Mol Plant-Microbe Int 13:159-169

8. Jansen C, Wettstein Dv, Shafer W, Kogel KH, Felk A, Maier FJ (2005) Infection patterns in barley and wheat spikes inoculated with wild-type and trichodiene synthase gene disrupted Fusarium graminearum. Proc Natl Acad Sci, USA 102:16892-16897

9. Guenther JC, Trail F (2005) The development and differentiation of Gibberella zeae (anamorph: Fusarium graminearum) during colonization of wheat. Mycologia 97: 229-237

10. Rittenour WR, Harris SD (2010) An in vitro method for the analysis of infection-related morphogenesis in Fusarium graminearum. Mol Plant Pathol 11:361-369 